\title{
ERRATUM
}

I. Waernbaum • G. Blohmé • J. Östman •

G. Sundkvist $\cdot$ J. W. Eriksson $\cdot$ H. J. Arnqvist •

J. Bolinder · L. Nyström

\section{Excess mortality in incident cases of diabetes mellitus aged 15 to 34 years at diagnosis: a population-based study (DISS) in Sweden}

Received: 13 May 2005 / Accepted: 4 November 2005 / Published online: 7 April 2006

C) Springer-Verlag 2006

Unfortunately, the legend for Fig. 3 was incorrect. The correct figure and legend are reproduced below.

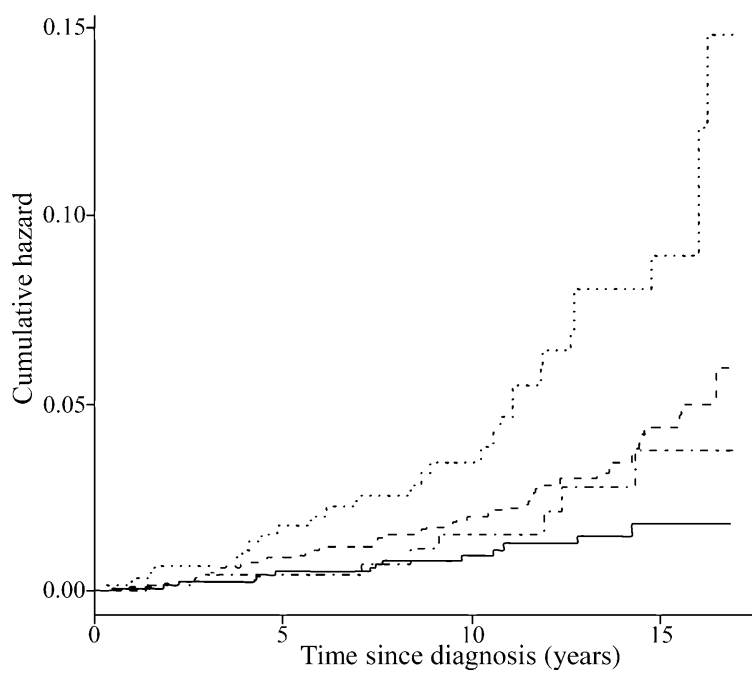

Fig. 3 Estimated cumulative hazard functions, stratified by sex and type of diabetes (secondary diabetes excluded). Dashed line, men with type 1 diabetes; continuous line, women with type 1 diabetes; dotted line, men with type 2 diabetes; dotted and dashed line, women with type 2 diabetes

\footnotetext{
I. Waernbaum $(\bowtie) \cdot$ L. Nyström

Department of Public Health and Clinical Medicine,

Division of Epidemiology and Public Health Sciences,

Umeå University,

Umeå, Sweden

e-mail: Ingeborg.Waernbaum@stat.umu.se

Tel.: +49-90-786-5571

Fax: +49-786-6614

G. Blohmé

Department of Medicine, South Hospital,

Stockholm, Sweden

J. Östman · J. Bolinder

Department of Endocrinology, Metabolism \& Diabetes, Karolinska University Hospital,

Huddinge, Sweden
}

\section{G. Sundkvist}

Department of Endocrinology,

Malmö University Hospital,

Malmö, Sweden

J. W. Eriksson

Department of Public Health and Clinical Medicine,

Division of Internal Medicine, Umeå University,

Umeå, Sweden

H. J. Arnqvist

Department of Medicine, Linköping University Hospital,

Linköping, Sweden

I. Waernbaum

Department of Statistics, Umeå University,

SE-901 87 Umeå, Sweden 